\title{
REGISTRO CIVIL NACIONAL E A PROTEÇÃO DE DADOS PESSOAIS NO BRASIL
}

\section{NATIONAL CIVIL REGISTRATION AND PERSONAL DATA PROCESSING IN BRAZIL}

\author{
${ }^{1}$ Rafael Copetti \\ ${ }^{2}$ José Renato Gaziero Cella
}

\section{RESUMO}

O trabalho realiza uma análise da proteção de dados pessoais no Brasil, em especial a partir da forma como os dados são captados. Busca-se fazer uma análise da proposta de criação de um documento único no Brasil e o respeito ao direito fundamental à privacidade. É utilizado o método de abordagem hipotético-dedutivo e, como método de procedimento, estudo de caso do projeto de lei que pretende instituir o Registro Civil Nacional. Ao final, é possível perceber a necessidade da publicação de instrumento legal de proteção dos dados pessoais sendo propostos mecanismos que se demonstram eficazes para proteção dos dados pessoais.

Palavras-chave: Privacidade, Cadastro eleitoral, Registro civil nacional, Proteção dados pessoais, União europeia

\begin{abstract}
The study makes an analysis of personal data protection in Brazil, mainly from the way data are collected. It aims analyzing the proposal of creating a single document in Brazil and respect to the fundamental right to privacy. The hypothetical-deductive method is used and, as a method of procedure, it is performed a case study of the law project that seeks to establish the National Civil Registration. At last, it is possible to notice the need of a legal instrument publication for protection of personal data and are propose mechanisms that turn out to be effective for protecting personal data.
\end{abstract}

Keywords: Privacy, Electoral registration, National civil registration, Personal data protection, European union

\footnotetext{
${ }^{1}$ Mestrando pela Faculdade Meridional - IMED, Passo Fundo, Rio Grande do Sul, (Brasil). Linha de Pesquisa: Fundamentos do Direito e da Democracia, Especialista em Direito Público IMED. Servidor Público Federal do Tribunal Regional Eleitoral do Rio Grande do Sul - TRE, Brasil. E-mail: rafaelcopetti@yahoo.com.br

${ }^{2}$ Doutor em Filosofia e Teoria do Direito pela Universidade Federal de Santa Catarina - UFSC, Florianópolis, Santa Catarina, Brasil. Professor pela Faculdade Meridional - IMED, Passo Fundo, Rio Grande do Sul, Brasil. E-mail: cella@cella.com.br
} 


\section{INTRODUÇÃO}

Com a evolução e aplicação das novas tecnologias nos diversos setores sociais, as pessoas estão cada vez mais expostas nas suas relações, sejam elas privadas ou públicas. As informações são coletadas de diferentes formas, na navegação ou cadastros em páginas da internet, fornecidas diretamente pelo usuário, em bancos de dados de diversas fontes ou como requisitos para a obtenção de determinado serviço ou documento perante o Poder Público.

Um exemplo típico é o fornecimento de dados biométricos pelas pessoas que solicitam a emissão do título de eleitor nos Cartórios Eleitorais do Brasil. O indivíduo, além de fornecer informações de caráter pessoal (nome, filiação, data de nascimento, sexo, endereço residencial ou comercial, tempo de vínculo com o município, se possui ou não irmão gêmeo, telefones, escolaridade e profissão), tem sua assinatura coletada digital e fisicamente. Uma fotografia e as digitais dos dez dedos das mãos igualmente são coletadas, muito embora apenas a identificação na urna eletrônica seja realizada por meio dos dedos polegares ou indicadores tão somente. Deve-se lembrar que o voto é obrigatório para todas as pessoas maiores de 18 anos e menores de 70 anos, conforme o ordenamento constitucional brasileiro.

Tanto os dados coletados pela Justiça Eleitoral, órgão do Poder Judiciário Federal, assim como os coletados por outros entes da Administração Pública, devem receber proteção jurídica adequada. Não apenas a coleta, mas da mesma forma o armazenamento e o tratamento de dados necessitam de tutela jurídica.

Afinal, trata-se de dados pessoais relativos à personalidade da pessoa, a aspectos da vida privada e que podem comprometer a imagem do indivíduo perante terceiros, sua moral e estrutura psíquica quando indevidamente utilizados ou tornados públicos.

Especial atenção é necessária à captação, tratamento e utilização de informações pessoais por órgãos públicos. Os dados essenciais fornecidos para obtenção do título de eleitor e a novel intenção legislativa de compartilhá-los para elaboração de um documento nacional único (Projeto de Lei ${ }^{\circ}$ 1.775/2015) configuram um exemplo relevante e questionável acerca da segurança e legalidade.

O intuito é que o RCN se utilize da base de dados biométricos da Justiça Eleitoral, do Sistema Nacional de Informações de Registro Civil (Sirc) e de outros órgãos.

Assim, como problema do presente estudo, surge o questionamento se o atual sistema normativo brasileiro apresenta mecanismos para uma efetiva proteção dos dados pessoais constantes nos bancos de dados estatais e privados? 
Preliminarmente a hipótese para o problema apresenta-se como negativa, pois o sistema jurídico carece da implementação de uma legislação específica sobre a proteção de dados pessoais. Além de não existir uma cultura de preservar essas informações do acesso ou tratamento indiscriminado, não há balizas para que os procedimentos respeitem à privacidade dos interessados.

Assim busca-se fazer uma análise da proposta de criação de um registro ou documento único no Brasil e o respeito ao direito fundamental à privacidade.

Especificamente é objetivo demonstrar a atual concepção da privacidade no contexto das novas tecnologias; verificar a existência de instrumentos jurídico-normativos de proteção dos dados pessoais no Direito brasileiro e no Direito Europeu, dando-se ênfase à legislação espanhola; estudar os fundamentos do projeto de lei que institui o Registro Civil Nacional e que atribuem competência para o controle do banco de dados pessoais a um órgão do Poder Judiciário.

A pesquisa utiliza o método de abordagem hipotético-dedutivo, partindo de um marco teórico geral aos mais específicos sobre o tema, contextualizando a privacidade e a regime jurídico de proteção de dados no Brasil. É realizado, como método de procedimento, estudo de caso do projeto de lei que pretende instituir o Registro Civil Nacional, coletando-se dados na proposta apresentada no Congresso Nacional, notícias disponibilizadas nos meios de comunicação e discussões em estudos científicos.

Ao final, é possível perceber a necessidade de um aprofundamento teórico no tema da proteção dos dados pessoais no Brasil, sob pena de colocar em risco substancial direito fundamental. São propostos mecanismos que se demonstram eficazes para proteção dos dados pessoais. E, ainda, percebe-se a necessidade de se adequar a legislação brasileiro, criando um sistema de identificação do cidadão com salvaguardas, definindo responsabilidades, controles, supervisão, e que permita ao interessado um maior controle sobre a forma com que os seus dados são manipulados ou processados.

\section{A PRIVACIDAde E O REgIME JURÍdico DE PROTEÇÃo DE DADOS BRASILEIRO}

Ao falar sobre a proteção jurídica da privacidade, da vida privada ou da intimidade, Doneda (2006, p. 101), assevera acerca da definição do tema: 


\begin{abstract}
Ao se tratar da privacidade, há de se fazer antes de tudo um esclarecimentoinicial sobre a terminologia utilizada. A profusão de termos utilizados pela doutrina brasileira para representa-la, propriamente ou não, é considerável; além de 'privacidade' propriamente dito, podem ser lembrados os termos: vida privada, intimidade, segredo, sigilo, recato, reserva, intimidade da vida privada, e outros menos utilizados, como 'privatividade' e 'privaticidade', por exemplo. O fato da doutrina estrangeira apontar igualmente para uma multiplicidade de alternativas certamente contribui, induzindo juristas brasileiros a experimentar diversas destas.
\end{abstract}

De acordo com Limberger (2007, p. 116), a intimidade como direito fundamental tem sua gênese na "[...] dignidade humana e está vinculado à própria personalidade, sendo seu núcleo central. Como direito que é da expressão da própria pessoa, desfruta da mais alta proteção constitucional”. Para a autora, “[...] As exigências do mundo tecnológico atual fizeram com que o direito tutelasse essa nova face da intimidade. A intimidade deriva da dignidade humana, é um direito fundamental que integra a personalidade. Das relações da informática e a intimidade se desenvolve a autodeterminação informativa. [...]" (LIMBERGER, 2007, p. 119).

Para Rodotá (1995, p. 122), a privacidade é "[...] o direito de manter o controle sobre as próprias informações e de determinar as modalidades de construção da própria esfera privada $[\ldots] "$.

No direito brasileiro, o direito à privacidade pode ser entendido como um direito da personalidade de matiz constitucional, com expressa previsão no artigo $5^{\circ}$, inciso $\mathrm{X}$, da Constituição da República.

Infraconstitucionalmente, a proteção da privacidade se consubstancia na cláusula geral estabelecida no artigo 21 do Código Civil. Ainda, destaca-se que as previsões legislativas específicas para a proteção de dados são escassas. Tem-se, na Lei 8.078/90 - Código de Defesa do Consumidor, a regulamentação dos bancos de dados e cadastros de consumidores em único dispositivo, o artigo 43. Além disso, há a regulamentação do chamado cadastro positivo pela Lei 12.414/2011, que disciplina a formação e consulta a bancos de dados com informações de adimplemento, de pessoas naturais ou de pessoas jurídicas, para formação de histórico de crédito.

No presente estudo, a privacidade é concebida

[...] como um direito fundamental, em sentido amplo, capaz de recepcionar em seu bojo a proteção da vida privada, da intimidade, da imagem, da honra e dos direitosbase vinculados ao conceito de direitos de privacidade na internet, significa dizer que, na contemporaneidade, o direito de navegar na internet com privacidade, o direito de monitorar quem monitora, o direito de deletar dados pessoais e o direito de proteger a identidade online devem ser tutelados, explícita e expressamente, 
como um dos pilares de garantia da eficácia do direito fundamental à privacidade em sentido amplo. (FORTES, 2015, p. 188).

A proteção dos dados no sistema normativo da União Europeia (UE) é tratada por meio de um sistema de regulamentos e diretivas, na qual é possível encontrar aspectos pioneiros no regramento da matéria. Há registro de legislações, por exemplo, na Alemanha e Suécia desde a década de 70. Portugal, em 1976, e, posteriormente, Espanha, 1978, foram os primeiros países a elevar a proteção em nível constitucional, trazendo previsões expressas nas respectivas Cartas.

Atualmente, as Diretivas 95/46/CE e 2002/58/CE, e Regulamento 45/2001, trazem diretrizes apra os países integrantes da UE. Ganham destaque também os Relatórios e Comunicações de acompanhamento da implantação e eficiência das normativas (FORTES, 2015, p. 132-133).

Cabe mencionar que desde o início de 2012 foi formada a Comissão Europeia para regulamentação sobre a proteção de dados pessoais. Entre os objetivos expostos há referência que

\footnotetext{
La Comisión europea quiere modernizar la legislación europea de protección de datos para garantizar la intimidad de los consumidores y hacerla compatible con la libre circulación de datos en la UE. . [...]

Las empresas sólo estarán autorizadas a enviar información personal fuera de la UE a países con un nivel similar en sus sistemas de protección de datos. Se trata además de mejorar y simplificar los mecanismos de transferencia internacional de datos. [...]

El objetivo de la nueva estrategia es consolidar un enfoque común en toda la UE. Las divergencias actuales no permiten determinar con nitidez la legislación aplicable en cada caso. Por eso es necesario armonizar las normas y reforzar el poder de las autoridades de protección de datos con el principio de cooperación y coordinación. (COMISIÓN EUROPEA, 2010).
}

Referidas premissas servem ao mesmo tempo de alerta à constante mutação e evolução da tecnologia e da forma com os dados podem ser armazenados e manipulados. É importante, ainda, considerar a facilidade do intercâmbio de informações e procurar meios para que essa circulação atenda requisitos de segurança e preservação da privacidade.

A utilização dos recursos tecnológicos alterou significativamente a circulação, a forma de compartilhamento e o armazenamento de dados. A digitalização de documentos e o arquivamento de informações em bancos de dados digitais é cada vez mais significativo.

Nesse contexto, a proteção de dados pessoais nos sistemas jurídicos em geral necessita uma análise mais criteriosa, principalmente no sistema jurídico brasileiro, no qual não se tem uma legislação específica acerca da proteção dos dados pessoais. 
Ao contrário da legislação encontrada em países da Europa, não há no sistema jurídico brasileiro, por exemplo, uma autoridade responsável e independente, dedicada a preservar o consentimento e o uso de dados pessoais mediante a supervisão do cumprimento das obrigações dos responsáveis pelo tratamento de dados, as quais possuem previsão específica. (GALINDO, 2013, p. 136).

De acordo com a normativa europeia, em caso de descumprimento, qualquer cidadão pode reclamar à autoridade de proteção dos dados, a qual estará apta a instaurar procedimento administrativo e aplicar sanções ao responsável. Referida característica, conforme Galindo (2013, p. 137), é relevante, pois:

se completó este cuadro de derechos y obligaciones con la atribución legal a la autoridad de protección de datos de su obligación de velar por el cumplimiento de las medidas conducentes a evitar la modificación de los datos personales por la utilización de las técnicas de seguridad de las TIC consideradas más adecuadas en cada momento.

A existência de autoridade responsável pela proteção dos dados, com atribuições claras e voltadas a não transgressão dos dados pessoais afigura-se, portanto, um relevante mecanismo.

\section{AUTODETERMINAÇÃO INFORMATIVA}

A autodeterminação informativa é um direito que orienta até hoje a proteção de dados pessoais na Alemanha e exerce grande influência em países do sistsema jurídico romanogermânico. "Concebido como um direito fundamental (...), o direito à autodeterminação informativa proporciona ao indivíduo o controle sobre suas informações" (DONEDA, 2006, p. 196-197).

Um julgamento (BverfGE 65,1) emblamático do Tribunal Constitucional Federal da Alemanha, em 15 de dezembro de 1983, foi o qual se averiguou a constitucionalidade da lei que ordenava o recenseamento geral da população, com dados sobre a profissão, moradia e local de trabalho para fins estatísticos.

Segundo o Tribunal Constitucional Federal da Alemanha, em virtude das condições do moderno processamento de dados, o direito geral da personalidade contido no artigo 2 I GG, em conjugação com o artigo 1 I GG, passa a abranger a proteção do indivíduo contra levantamento, armazenagem, uso e transmissão irrestritos de seus dados pessoais, que somente podem ser utilizados, em princípio, com sua autorização. Essa norma consubstancia 
um direito geral à autodeterminação sobre a informação, que somente é restringível se houver a contraposição de um interesse predominante da coletividade (SCHWABE, 2005, p. 233235).

Na construção dessa norma concreta, o Tribunal Constitucional Federal da Alemanha considerou que o direito ao livre desenvolvimento da personalidade abrange o poder do indivíduo de decidir, por si próprio, quando, quais e em que limites os fatos pessoais serão revelados, poder que, diante da evolução tecnológica atinente ao processamento automático de dados, depende de uma proteção especialmente intensa. (SCHWABE, 2005, p. 237).

A faculdade contemporânea e futura de armazenamento ilimitado, transmissão instantânea e consulta irrestrita de dados atentaria contra a autodeterminação individual, uma vez que não mais possibilitaria a determinação, com segurança, de quais informações sobre a sua pessoa são conhecidas nem por quem são acessadas, inibindo substancialmente a liberdade de planejar ou decidir com autodeterminação. (SCHWABE, 2005, p. 237).

Esse direito à autodeterminação informativa, porém, não é absoluto, mas restrito quanto às informações de interesse geral predominante, quer dizer, limitável excepcionalmente quando imprescindível para a consecução de um interesse público. Tais restrições exigem uma base constitucional que possibilite o conhecimento pelo cidadão, de forma clara e reconhecível, dos pressupostos e da extensão das limitações, atendendo ao princípio da transparência (ou clareza normativa) do Estado de Direito. (SCHWABE, 2005, p. 237-239).

Entre a importância da decisão citada, na qual se concebe o autodeterminação informativa como direito fundamental, aponta Mario Panebianco (apud DONEDA, 2006, p. 197), há que se destacar que assertiva que "Os direitos fundamentais não são concedidos ao cidadão para que deles disponha livremente, porém na sua condição de membro da comunidade e também no interesse público".

Na espanha, a tema igualmente tem acolhida, sendo que a sentença 254/93 do Tribunal Constitucional Espanhol é considerada uma referência na matéria. É a partir dela que se acentuam as discussões acerca do surgimento de um novo direito fundamental (da autodeterminação informativa) ou uma evolução do que seria o direito à intimidade.

Murillo (2009, p. 34) menciona que na STC 292/2000 há várias referências ao direito fundamental da proteção de dados, diferenciando-o da intimidade. Pois se compartilham o objetivo de oferecer uma eficaz proteção constitucional da vida privada pessoal e familiar, aquele atribui ao titular a faculdade a seu titular uma séria de faculdades que consiste em sua 
maior parte no poder jurídico de impor a terceiros a realização ou omissão de determinados comportamentoscuja concreta regulação debe estabelecer a lei.

O núcleo da autodeterminação informativa, enquanto relacionada ao aspecto básico do direito à intimidade, constitui-se na faculdade que a pessoa detém de escolher sobre a divulgação, revelação, ou não de informações que diretamente a ela se referem. Isso porque a intimidade, mais que um estado de autoconfinamento, supõe uma qualidade na interação entre os indivíduos: trata-se de uma condição ou qualidade social da pessoa, que é objeto de tutela constitucional na medida em que esta pode ter o legítimo direito a não revelar aos demais determinados aspectos de suas relacões com outras pessoas, que o titular do direito julga devam permanecer em um plano reservado ao privado. (PODLECH apud PERÉZ LUÑO, 2012, p. 93).

Para Doneda (2006, p. 201) a terminologia mais adequada (e simples) é tão somente "proteção de dados pessoais", pois estaria englobada tanto a problemática da privacidade quanto a da informação, que teria como ponto de referência os direitos da personalidade e estaria isenta de uma acepção patrimonialista ou contratual, ao mesmo tempo em que não remonta ao direito à liberdade em uma acapção demasiado ampla.

A critíca do jurista citado reside basicamente em três fatores. O primeiro é acerca da correta definiçaõdo que seja autodeterminação, pois em determinado sentido poderia dar ao indivíduo a oportunidade de controlar as informações que lhe digam respetio, dentro de parâmatetros de ampla informação solidariedade (DONEDA, 2006, p. 198).

Já para uma leitura em chave liberal a autodeterminação concentrar-se-ia no ato do consentimento da pessoa para o tratamento de seus dados pessoais e assumiria contornos negociais, afastando a matéria do âmbito dos direitos da personalidade. (DONEDA, 2006, p. 198).

Por fim, outro problema é a possibilidade de ter a impressão de que as pessoas teriam um direito de propriedade sobre suas informações, o que as transportaria para o campo das situações patrimoniais. (DONEDA, 2006, p. 198-1999).

Trata-se de direito que orienta até hoje a proteção de dados pessoais na Alemanha e exerce grande influência em países do sistema jurídico romano-germânico, encontrando acolhida também no Tribunal Constitucional Espanhol na sua sentença 254/93 (DONEDA, 2006, p. 196-197).

De acordo com Fortes (2015, p. 134), é preciso ressaltar “[...] a fundamental importância do conceito de autodeterminação informacional, instituído na vanguarda 
normativa alemã, e que constitui a gênese normativa da proteção de dados pessoais no continente europeu [...]".

\section{AUTORIDADE INDEPEDENTE}

Outro aspecto a ser delimitado é a importância da existência de um órgão responsável pela proteção dos dados pessoais. Trata-se de órgão com diversas atribuições sociais, políticas e jurídicas, pois, como se observa em experiências europeias, além de fiscalizar, controlar e aplicar sanções à violação dos dados pessoais, cabe a promoção de ações educativas e de informação tanto para cidadãos quanto para órgãos públicos.

É preciso delimitar as atribuições, estrutura, composição e observar uma autonomia financeira e política a esse órgão. A vinculação a órgãos governamentais e ligados ao Poder Executivo não é desejável. Ainda, a dependência ao Poder Legislativo, Judiciário ou outros da estrutura jurídico-administrativa (Ministério Público, por exemplo) também podem comprometer a segurança dos dados, notadamente pelo interesse em determinadas demandas.

O novo órgão deve ter autonomia e meios efetivos de executar sanções aos infratores, além de organizar as políticas para a conscientização quanto à utilização e guarda de dados pessoais.

Ademais, sua composição deverá ser híbrida e seus integrantes oriundos de diversos segmentos sociais. Ao mesmo tempo em que é importante que se tenha um órgão com conhecimentos técnicos acerca da criação e manutenção de banco de dados é importante que haja uma interdisciplinaridade em seu Conselho administrativo.

Nesse sentido, referidos integrantes poderão advir de diferentes áreas do conhecimento contribuindo para uma melhor regulamentação da legislação protetiva e adequação à realidade das relações sociais e institucionais.

Conforme destacada no trabalho, o Agência Espanhola de Proteção de Dados é dirigida por um presidente eleito entre os membros do Conselho Consultivo, o qual é formado por representantes de cada uma das casas do Poder Legislativo, um representante indicado pelo governo central, outro proposto pelas administrações locais concentradas na Federação Espanhola de Municípios e Províncias, um membro da Academia Real de História, um técnico no assunto selecionado pelo Conselho Superior de Universidades, um representante dos consumidores e usuários, além de um representante do setor de banco de dados privados.

A presença de membros dos Poderes Executivo, Legislativo, Judiciário tende a manter a ideia da sistema de controle e execução de cada uma das atividades a que se lhes 
atribui constitucionalmente. Os Estados federados, seja por meio de associações ou entidades representativas por regiões geográficas, podem igualmente indicar membro(s) no sentido de procurar trazer uma contribuição acerca das distintas realidades nas regiões brasileiras. Representantes oriundos de entes educacionais e setores de tecnologia e informação contribuem para uma visão diferenciada da regulação dos arquivos.

Referida inter-relação faz com que tanto questões política-econômico-sociais e técnicas sejam levadas em consideração tanto no momento de definições fundamentais na proteção dos dados por meio de instrumentos regulatórios quanto no julgamento dos casos concretos a ela submetidos.

Ao falar sobre a independência de uma autoridade independente de proteção de dados, Doneda (2006, p. 393) afirma que referida característica pressupõe a presença de "mecanismos de nomeação de seus membros, geralmente limitando a discricionariedade na sua escolha (através, por exemplo, da exigência de determinada formação ou atuação profissional)", além "da incompatibilidade de sua atuação com outras atividades, atuais ou mesmo pregressas (e também futuras [...]), além da limitação temporal de seu cargo" (DONEDA, 2006, p. 393).

Ainda, a independência pressupõe "a ausência de ingerência governamental sobre seus atos, que se pode obter situando tais órgãos fora de uma posição hierárquica em relação ao governo" (DONEDA, 2006, 393-394).

Além da especificidade referente à matéria e da função de velar pela fiel cumprimento e respeito à lei, interpretando-a e aplicando-a, o ente independente deve ser dotado de poderes para inspecionar e aplicar sanções. É preciso que os responsáveis pelos arquivos mantenham referido órgão informado acerca das características de seu banco, além de, sendo o caso, quando requisitados, deem acesso aos dados que nele constam.

\section{REGISTRO CIVIL NACIONAL E OBSERVAÇÂNCIA DA PROTEÇÃO DE DADOS PESSOAIS}

O Projeto-Lei encaminhado pela Presidente da República em conjunto com o Presidente do Tribunal Superior Eleitoral (TSE) ao Congresso Nacional com intuito de implantar o Registro Civil Nacional (RCN) e o documento de RCN tem implicações diretas sobre o tema da proteção dos dados pessoais. A mensagem $\mathrm{n}^{\mathbf{0}} 192$, referente ao encaminhamento, foi publicada no dia 29 de maio de 2015 no Diário Oficial da União 
(BRASIL, 2015, p. 1). A ideia central é que as unidades da Justiça Eleitoral atribuam a cada brasileiro um número de RCN e forneça o documento

O intuito é que o RCN utilize a base de dados biométricos da Justiça Eleitoral, do Sistema Nacional de Informações de Registro Civil (Sirc) e de outros órgãos não especificados no projeto de lei.

O Registro Civil Nacional (RCN) estabelece uma identificação centralizada do cidadão brasileiro pelo Poder Judiciário (Justiça Eleitoral), desde o seu nascimento até o seu óbito (incluindo eventuais mudanças de estado e capacidade civil). Identifica o cidadão, nato ou naturalizado, pelo batimento de suas impressões digitais e faciais com a de todos os demais cidadãos brasileiros constantes em uma base de dados. (TRIBUNAL SUPERIOR ELEITORAL, 2015c).

Conforme a sistemática a ser adotada, nos termos do item 5 das motivações anexas ao Projeto de Lei (BRASIL, 2015) e encaminhadas à Presidência da República, será atribuído um número de RCN pela Justiça Eleitoral, o qual permitirá identificar o cidadão com segurança. Ainda conforme o documento, não se pretende impor um documento único nem criar um documento novo, "pois o documento de RCN poderá futuramente substituir o título de eleitor e conterá diversas informações e números oriundos de outros órgãos do Poder Público, com a finalidade de simplificar, com segurança, a identificação do cidadão" (BRASIL, 2015, número 5).

A ideia de simplificação e desburocratização nas relações do Estado e as pessoas físicas e jurídicas, assim como nas interações entre estas últimas, é louvável. Um documento único, além de limitar a quantidade de números e códigos que são necessários numa relação entre as partes citadas, facilita a identificação das pessoas e centraliza as operações em um órgão específico.

Todavia, é preciso analisar se os direitos fundamentais do cidadão serão preservados, em última análise, a privacidade. Como sabido, a Justiça Eleitoral administra o maior cadastro de cidadãos de toda América Latina, que hoje conta com mais de 142 milhões de eleitores, sendo 30 milhões já registrados biometricamente. "Com o projeto, o poder Executivo da União, estados, Distrito Federal e municípios terão acesso à base de dados do RCN, com exceção das informações eleitorais" (TRIBUNAL SUPERIOR ELEITORAL, 2015).

Em entrevista, o Assessor-Chefe de Gestão Estratégica do Tribunal Superior Eleitoral (TSE), Paulo Camarão, afirmou que "a base de dados que será montada, permitindo uma interação dos Poderes Executivo, Legislativo e Judiciário, além da iniciativa privada, 
garantindo em todas as operações a unicidade de identificação do cidadão" (TRIBUNAL SUPERIOR ELEITORAL, 2015).

Perceptível, portanto, o interesse na troca de informações e interação dos dados não apenas entre os três poderes do União, mas, também, com órgãos privados.

Convêm destacar que a Constituição Federal (CF) prevê a Justiça Eleitoral como órgão do Poder Judiciário (art. 92, inc. V). Trata-se de Justiça Especializada com regulamentação nos arts. 118 a 121 do diploma constitucional e arts. 12 a 41 do Código Eleitoral (CE - Lei n ${ }^{\circ}$ 4.737/1965), com características peculiares em relação aos demais órgãos. Isso se constata em virtude de sua composição híbrida, pois não contém quadro próprio de magistrados e igualmente pela temporariedade dos mandatos, eis que estes são exercícios por períodos delimitados de tempo.

Para realizar que o indivíduo possa realizar a sua inscrição eleitoral, transferir seu domicilio eleitoral ou atualizar dados cadastrais é necessário que compareça pessoalmente ao Cartório Eleitoral do seu domicílio eleitoral. É possível realizar um pré-atendimento na página do TSE na internet, todavia, não dispensa o comparecimento. No caso de haver divergências nos dados cadastrais, não é possível realizar o agendamento na internet.

Entre os dados obrigatórios para o expedição do título de eleitor é possível destacar: nome, data de nascimento, nome da mãe, nome do pai, documento de identificação (com número e órgão expedidor), estado civil, sexo (masculino e feminino), Unidade da Federação (UF) e município de nascimento, grau de instrução, ocupação principal, informar se possui ou não irmão(ã) gêmeo(a). (TRIBUNAL SUPERIOR ELEITORAL, 2015b, 2015).

Ainda, obrigatoriamente deve ser informado, sé é portador de necessidade especial (informando se essa deficiência é visual, de locomoção, outros, visual e locomoção, visual e outros, locomoção e outros, visual, locomoção e outros), código endereçamento postal (CEP), UF e município de residência, logradouro, tempo (anos e meses) de domicílio no município em que esta realizando a operação, escolha do local de votação. (TRIBUNAL SUPERIOR ELEITORAL, 2015b, 2015).

Não aparecerem como campos obrigatórios, embora disponíveis para preenchimento, o $\mathrm{CPF}$, número da residência, complemento deste último campo e dois números de telefone. (TRIBUNAL SUPERIOR ELEITORAL, 2015b, 2015).

Juntamente com a coleta dessas informações, a Justiça Eleitoral vem atualizando seu cadastro de eleitores com informações biométricas. Em outras palavras, como requisito para a confecção do título de eleitor será preciso que o eleitor, além de assinar em um aparelho eletrônico, tenha uma fotografia e as digitais dos dez dedos coletadas. 
Portanto, é preciso refletir acerca controle desses dados relativos à personalidade do indivíduo (sexo, escolaridade, residência, data de nascimento, filiação, entre outros), assim como os biométricos (assinatura digital, foto e impressões digitais dos dedos de ambas as mãos) por órgão do Poder Judiciário. Em especial no ordenamento jurídico brasileiro que, como referido, não disciplina a matéria.

A centralização de informações em um único banco de dados facilita o acesso a detalhes privados da vida dos cidadãos. Ainda mais na sociedade atual, permeada por dispositivos informáticos que permitem o processamento de milhares de informações a partir de apenas um click e possibilita que a informação circule ao redor do mundo com celeridade impressionante.

As tecnologias utilizadas, combinadas com outras informações, como, por exemplo, a utilização de senhas de acesso e dados biométricos, fazem com que se individualize o usuário e seja possível traçar um perfil baseado nas suas atividades diárias e movimentações financeiras.

Dados cujo interesse é de grande relevância e e imensurável valor, tanto na iniciativa privada quanto pública. Na primeira, é possível citar (apenas a título exemplificativo) o interesse de empresas que vender produtos aos usuários baseadas em atividades recentes ou um perfil construído pelo conjunto de dados tratadas. Ao poder público para utilização em programas assistenciais direcionados àquelas pessoas com baixa condição de renda. Isso apenas ficar em exemplos que, em tese, pode cingir ao âmbito de atividades que, em tese, podem ser lícitas.

A ausência de uma legislação protetiva dos dados pessoais torna ainda mais temerária uma centralização de dados. É preciso a observância dos princípios protetivos na coleta, tratamento e armazenamento. Além disso, uma definição clara de responsabilidades e funções, em outras palavras, um sistema de salvaguardas ao direito constitucional da privacidade.

Reunir todas as informações em um único documento tem um grande potencial de fragilizar os sistemas de proteção de dados pessoais passíveis de ser implantados, na medida em que uma possível vulneração do documento único permitirá o acesso indevido a todos os dados relevantes, inclusive dados sensíveis, do cidadão. Ainda, são disponibilizadas às autoridades estatais informações que não lhes seria legítimo aceder, com a elevação de exercício de controles nem sempre utilizados de forma adequada. (CELLA, ARNS DE OLIVEIRA, 2015). 
Não que tange à imposição de sanções em caso de eventual transgressão aos limites objetivamente definidos na legislação, cabe destacar que não basta apenas a aplicação de sanções pecuniárias e cujo arbitramento fique ao alvitre do julgador. É preciso que sejam estabelecidos balizas na própria lei de forma proporcional à gravidade da norma postula, de forma que tanto quem irá concretizar a norma ou aquele que a viola tenha possibilidade de saber as consequências dos atos. Do contrário, corre-se o risco de patrimonializar o direito à privacidade, o qual, na realidade, está diretamente relacionado à personalidade do indivíduo.

\section{CONCLUSÃO}

O tema da privacidade tem relação direta com o nível de desenvolvimento tecnológico da sociedade. Conforme se prolifera o uso das novas tecnologias no meio social, aumenta a necessidade de se pensar as relações de poder, transparência e autonomia individual na sociedade.

O uso de produtos tecnológicos tem crescido significativamente nos últimos anos e tem sido influenciado a rotina das pessoas. Estas passam várias horas em frente à tela do computador, de um smartphone ou tablet. Utiliza-se as redes sociais e blogs para comunicação e divulgação de informações. As informações são buscadas e armazenas em diversas fontes do ciberespaço ou meio digital.

Na era da informação o tema proteção dos dados pessoais ganha ainda mais relevância, pois a facilidade do acesso a dados e informações e a utilização de recursos e mídias sociais os deixam vulneráveis.

É preciso que os instrumentos normativos estejam em consonância com a aludida mutabilidade social oriunda célere evolução tecnológica. É importante que as normativas acompanhem as novas descobertas científicas, devendo, quando menos, existirem diretrizes transparentes e objetivas que permitam a adaptação legislativa.

O sistema jurídico de proteção dos dados pessoais deve ser constituído de uma estrutura sólida, que dê transparência e que estabelece uma sistema de identificação e armazenamento de dados com salvaguarda. É necessária uma definição claro acerca de quem controla, quem fiscaliza, quem é responsável e a forma como os dados podem ser compartilhados.

No presente estudo foi verificado que o sistema jurídico brasileiro não apresenta as características citadas, confirmando a hipótese inicial. Especialmente por inexistir uma lei de 
proteção de dados pessoais. Referido instrumento legal permitiria que se estabelecem parâmetros à efetivação do direito fundamental, impedindo o uso e tratamento ilegal de informações acerca da vida privada das pessoas.

A criação de um documento de identificação único, ainda mais nos moldes da atual proposta do Registro Civil Nacional, compromete o direito à privacidade do cidadão. O projeto permite o compartilhamento de dados sensíveis do cidadão tanto entre instituições públicas quanto privadas. Ao mesmo tempo, não existem parâmetros acerca do controle e responsabilidade no tratamento dessas informações.

$\mathrm{O}$ uso indiscriminado desses dados além de vulnerar direito fundamental facilita o controle e monitoramento dos cidadãos. Pois conforme afirmado, com o emprego de tecnologias de informação e comunicação fica mais fácil classificar dados e individualizar as pessoas.

O controle dos dados e informações deve ter um controle mais amplo pelo próprio indivíduo, o qual necessita ter acesso às informações armazenadas nos bancos de dados a seu respeito, podendo exigir a sua retirada ou alteração e atualização. Busca-se, em última análise, a correção dos dados, conhecimento pelo indivíduo acerca da existência de cadastro e do que consta a seu respeito.

Ademais, a criação de uma autoridade independente pode contribuir, a exemplo do direito europeu, para a efetivação proteção dos dados. Nos moldes apresentados trata-se de ente multidisciplinar, mas ao mesmo tempo especializado no tema, sem subordinação a órgãos estatais e privados.

Outra vantagem de referida autoridade é resolver as demandas ainda no âmbito administrativo, sem necessidade de se recorrer ao Poder Judiciário. Todavia, é preciso que tanto procedimento, funções, sanções e demais atribuições estejam previstas em legislação específica.

Portanto, é imprescindível a existente de uma legislação protetiva dos dados pessoais no sistema jurídico brasileiro para garantia da privacidade dos cidadãos. É a partir de parâmetros claros, transparentes, e com a especificação de princípios, direitos e deveres acerca do tema que projetos como o Registro Civil Nacional podem obter êxitos sem que se vulnere dados pessoais ou, quando menos, os coloque em risco em razão de uma proteção deficiente.

\section{REFERÊNCIAS}


BRASIL. Mensagem no 192, de 28 de maio de 2015. Diário Oficial [da] República Federativa do Brasil, Presidência da República. Brasília, 29 mai. 2015. Seção1, p. 1.

CELLA, José Renato Gaziero; ARNS DE OLIVEIRA, Marlus H. A unificação do registro de identidade civil e a proteção de dados pessoais no Brasil. In: III Encontro de Internacionalização do CONPEDI, 2015, Madrid.

COMISIÓN EUROPEA. Estrategia de la ue para la protección de datos en internet. 2010. $<$ http://ec.europa.eu/spain/actualidad-y-prensa/noticias/internet-y-sociedad-de-lainformacion/proteccion-datos-internet-ue_es.htm>. Acesso em: 23 set. 2015.

DONEDA, Danilo. Da privacidade à proteção de dados pessoais. Rio de Janeiro: Renovar, 2006.

FORTES, Vinícius Borges. $\mathbf{O}$ direito fundamental à privacidade: uma proposta conceitual para a regulamentação da proteção dos dados pessoais na internet no Brasil. 2015. 225p. Tese (Doutorado em Direito) - Universidade Estácio de Sá, Rio de Janeiro, 2015.

GALINDO AYUDA, Fernando. Seguridad y sociedad del conocimiento. In: GALINDO, Fernando (ed.). EI derecho de la sociedad en red. Lefis Series, 14. Zaragoza: Prensas de la Universidad de Zaragoza, 2013. p. 129-154.

LIMBERGER, Têmis. $O$ direito à intimidade na era da informática: a necessidade de proteção dos dados pessoais. Porto Alegre: Livraria do Advogado, 2007.

RODOTÀ, Stefano. A vida na sociedade da vigilância: a privacidade hoje. Tradução: Danilo Doneda e Luciana Cabral Doneda. Rio de Janeiro: Renovar, 2008.

RODOTÀ, Stefano. Tecnologie e diritti. Bologna: II Mulino, 1995.

TRIBUNAL SUPERIOR ELEITORAL. Grupo de projetos especiais do TSE trabalha no desenvolvimento do RCN. 2015a. Disponível em: <http://www.tse.jus.br/imprensa/noticiastse/2015/Julho/grupo-de-projetos-especiais-do-tse-trabalha-no-desenvolvimento-do-rcn>. Acesso em: 24 jul. 2015.

TRIBUNAL SUPERIOR ELEITORAL. Pré-atendimento eleitoral - Título NET. 2015 b. Disponível em: <http://www.tse.jus.br/eleitor/servicos/pre-atendimento-eleitoral-titulonet/titulo-net>. Acesso em: 18 out. 2015. 